\title{
From reorienting of attention to biased competition: Evidence from hemifield effects
}

\author{
Sebastiaan Mathôt, Clayton Hickey, and Jan Theeuwes \\ Vrije Universiteit Amsterdam, Amsterdam, The Netherlands
}

\begin{abstract}
When a distractor was presented simultaneously with or directly following a target, it produced more interference when it was presented in the same visual hemifield as the target than when it was presented in the opposite visual field. This result is interpreted in terms of biased competition; there is more competition between stimuli when they are presented in the same visual field, rather than in opposite visual fields. However, when the distractor was presented $125 \mathrm{msec}$ or more prior to the target, this pattern was reversed. In those cases, there was more distractor interference when target and distractor were presented in opposite visual fields. This can be explained by assuming that attention was captured by the distractor, and that there was an additional cost of reorienting to a location in the opposite visual field.
\end{abstract}

As impulses travel upward in the hierarchy of visual brain areas, increasingly complex visual features are processed in a decreasingly localized manner (Smith, Singh, Williams, \& Greenlee, 2001). Because of the coarse localization in higher visual areas, stimuli presented near one another activate largely overlapping neural populations. It is difficult, therefore, to attribute neural activity unambiguously to a single stimulus (Desimone \& Duncan, 1995; Luck, Girelli, McDermott, \& Ford, 1997; Moran \& Desimone, 1985). The spiking of a neuron might indicate that one of the stimuli in its receptive field (RF) has a certain feature-but which stimulus?

It has become clear that visual attention plays a crucial role in the way these ambiguities are resolved. In a situation in which attention is unfocused, two nearby stimuli act in a mutually suppressive way (Kastner, De Weerd, Desimone, \& Ungerleider, 1998), so that both stimuli are weakly represented. Furthermore, the representations of the two stimuli are not clearly delineated, so that there is ambiguity in which features belong to which object (for a review, see Beck \& Kastner, 2009). However, if attention is directed to one of the stimuli, activation is driven largely by the attended stimulus and the visual system effectively becomes "blind" to the presence of the nonattended stimulus (Luck, Chelazzi, Hillyard, \& Desimone, 1997; Motter, 1993; Reynolds, Chelazzi, \& Desimone, 1999). Therefore, in a state of focused attention, the attended stimulus is strongly represented and ambiguity is resolved, since only features of a single object - the attended object - are represented. Phrased differently, nearby stimuli activate overlapping neural populations and therefore have to compete for representation in the visual system. Visual attention is what determines which stimulus wins this competition. These competitive interactions form the central tenet of many contemporary theories of attention, such as the biased competition model (Desimone, 1998; Desimone \& Duncan, 1995), the ambiguity resolution theory (Luck, Girelli, et al., 1997), and the selective tuning model of visual attention (Tsotsos et al., 1995).

As stimuli are spaced farther apart, there is decreasing overlap between the neural populations activated by their presentation. Since competition is believed to occur predominantly at the level of RFs, this results in less competition for representation (Beck \& Kastner, 2009; Hopf et al., 2006; but see Tombu \& Tsotsos, 2008). In addition, and of special importance to the present study, is the finding that there is also less competition if stimuli are presented in opposite visual fields (Sereno \& Kosslyn, 1991; Torralbo \& Beck, 2008). In part, this can be explained by the fact that the RFs of neurons in early visual areas tend to be confined to one visual field: The left visual field is processed in the right hemisphere, and vice versa (Desimone \& Schein, 1987; Gattass, Sousa, \& Gross, 1988). However, in the inferior temporal cortex, the majority of neurons have RFs that encompass part of both visual fields (Rocha-Miranda, Bender, Gross, \& Mishkin, 1975), and even in this area there is more competition if stimuli are presented in the same visual field than if they are presented in opposite visual fields (Chelazzi, Duncan, Miller, \& Desimone, 1998; Sato, 1988, 1989).

One of the most important predictions that can be derived from biased competition is that interference between stimuli should be strongest if stimuli are presented in proximity and within the same visual field. That this is the case has been known for quite some time (Pan \& Eriksen, 1993; Sereno \& Kosslyn, 1991), but not until recently has the link with biased competition been made explicit (Bahcall \& Kowler, 1999; Caputo \& Guerra, 1998; Cave

S. Mathôt, s.mathot@psy.vu.nl 
\& Zimmerman, 1997; Mounts, 2000; Torralbo \& Beck, 2008). Mounts and Gavett (2004) investigated the effects of biased competition in a behavioral paradigm. Participants were presented with an array of placeholders, followed by an array of stimuli, and performed a discrimination task using one of these stimuli (the target). Just before the search array was presented, two placeholders suddenly increased in size. The target was always presented at the location of one of these two placeholders. The crucial finding was that participants were faster to respond if the two possible target locations were spaced farther apart. Importantly, on top of this distance effect there was an effect of visual field: Participants were faster to respond if the two locations were on opposite sides of the vertical meridian. These findings are readily explained in terms of biased competition; the sudden increase in size of the two placeholders captured attention, thus facilitating processing of the stimuli, which were subsequently presented at these locations. However, the extent to which the two stimuli interfered with each other depended on the level of competition between them. Since competition is strongest between stimuli presented in proximity and in the same visual field, there was less interference, as measured by decreased reaction times (RTs), if they were spaced far apart and located in opposite visual fields.

Although the implications of biased competition for simultaneously presented stimuli are quite clear, less is known about the temporal characteristics of these competitive interactions. Therefore, an important question is how competition changes as a small delay is introduced between the presentation of two stimuli. A number of studies (Beck \& Kastner, 2005; Kastner et al., 1998; Kastner et al., 2001) have shown that competitive interactions are absent or strongly reduced if stimuli are presented sequentially. However, the intervals used in these studies are relatively long (250 msec between successive presentations), and the possibility remains that competition will occur when a target and a distractor are presented in close temporal succession. It is known that the neural response to a stationary object has a rapid initial buildup, then decreases over time (Keysers \& Perrett, 2002; Reynolds et al., 1999). The remaining sustained neural response elicited by a stimulus could compete for representation with another, subsequently presented stimulus. This would result in competition that would be less pronounced but similar to that found in studies in which stimuli are presented simultaneously (e.g., Torralbo \& Beck, 2008).

The present study followed up on previous research, which showed that competition is strongest between stimuli presented in the same visual field. We investigated how this hemifield effect changes over time, by varying the temporal interval between the presentation of two stimuli. To this end, we used an attentional capture paradigm (see, e.g., Theeuwes, 1994) in which participants responded to a target stimulus in the presence of an irrelevant onset distractor. In an attentional capture paradigm, the typical finding is that the presentation of an irrelevant onset disrupts processing of a target, as measured by increased RTs and decreased accuracy relative to a control condition (Theeuwes, 1991). Traditionally, this type of distrac- tor interference has been explained in terms of shifting attention: Attention is automatically pulled toward the distractor, and the voluntary process of reorienting toward the target takes time and effort (Jonides \& Yantis, 1988). However, this view fails to explain why distractor interference should be greatest if stimuli are presented in proximity or in the same visual field - at least if they are presented simultaneously. Rather, one might expect the opposite, since shifting attention between two nearby locations intuitively seems less costly than shifting attention across a large region of space. Biased competition offers a related but more concrete explanation: An irrelevant onset does indeed attract attention, but interference is due to the fact that the target initially "loses the competition" (Mounts, 2000). Because the strength of competition is inversely related to stimulus separation, there is less competition to be lost, therefore less distractor interference, if the target and the distractor are spaced far apart or presented in opposite visual fields.

In the present study, we presented a target and a distractor either simultaneously or sequentially, and either in the same or in opposite visual fields. As a control condition, we included trials in which the distractor was presented not as a single onset, but simultaneously with the premasks (see Figure 1). Our expectation was that when the target and the distractor are presented simultaneously, distractor interference is greater when the distractor and the target are presented in the same visual field than when they are presented at equal distance in opposite visual fields (Mounts \& Gavett, 2004; Sereno \& Kosslyn, 1991; Torralbo \& Beck, 2008). We did not expect competition to arise when there was a significant delay between the presentation of the target and the distractor. However, it is still an open question whether competitive interactions also occur, although perhaps to a lesser extent, if the distractor is presented slightly before the target. In Experiment 1, we investigated this by presenting a distractor simultaneously with or prior to the presentation of a target. Another important question is how processing of a target is disrupted by a subsequently presented distractor: Do competitive interactions play a role in this? We investigated this in Experiment 2, in which a distractor was presented simultaneously with or following the presentation of a target.

\section{EXPERIMENT 1}

\section{Method}

Participants. The observers were 25 students from the Vrije Universiteit, age range 17-25. For their participation, they received monetary compensation or course credit. All observers reported normal or corrected visual acuity and were naive as to the purpose of the experiment.

Apparatus. The experiment was run on a $2.6-\mathrm{GHz}$ Pentium 4 PC, using a 17-in. nonflat CRT display with a resolution of $1,024 \times$ 768 pixels. Manual responses were collected on a QWERTY keyboard. Three identical computer setups were used for experimental testing and colors were adjusted for each display separately. The experiment was conducted in a dimly lit room.

Stimuli. Each trial started with the presentation of a gray central fixation dot (radius $0.2^{\circ}$, luminance $29 \mathrm{~cd} / \mathrm{m}^{2}$ ) on a black display $\left(0.5 \mathrm{~cd} / \mathrm{m}^{2}\right)$. After $700 \mathrm{msec}$, a display consisting of six premasks 


\section{Time}

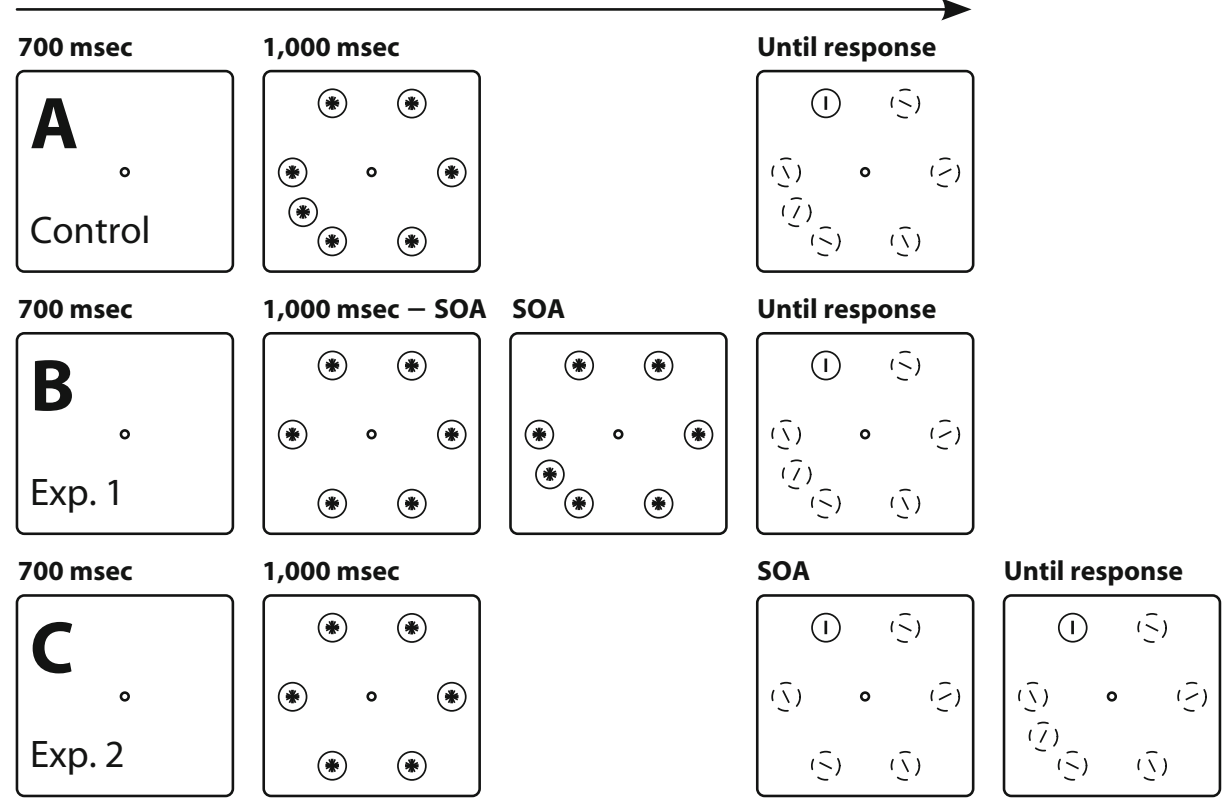

Figure 1. A schematic representation of the experimental paradigm. Dashed and continuous lines represent different colors. (A) The control condition for both experiments, in which the distractor was presented at the same time as the premasks. (B) In Experiment 1, the distractor was presented simultaneously with or at a variable SOA before the presentation of the target. (C) In Experiment 2, the distractor was presented simultaneously with or at a variable SOA after the presentation of the target.

(identically colored circles containing six lines) was presented (see Figure 1). Circles were presented equidistant from one another $\left(6.4^{\circ}\right)$ on a hypothetical circle with a radius of $12.4^{\circ}$. Each circle had a red (CIE $x, y$ chromaticity coordinates of $0.6,0.3)$ or green $(0.3,0.6)$ outline $\left(0.1^{\circ}\right)$ with a luminance of $12 \mathrm{~cd} / \mathrm{m}^{2}$. Each circle contained a premask consisting of six gray line segments $\left(0.03^{\circ} \times\right.$ $0.9^{\circ}, 29 \mathrm{~cd} / \mathrm{m}^{2}$ ), tilted $0^{\circ}, 20^{\circ}, 70^{\circ}, 90^{\circ}, 110^{\circ}, 160^{\circ}$, or $180^{\circ}$ from a vertical orientation. After $1,000 \mathrm{msec}$, the search array was presented. All circles except for the target circle changed color, and in each circle all but one line disappeared. In the nontarget circles, the remaining line was always tilted $20^{\circ}, 70^{\circ}, 110^{\circ}$, or $160^{\circ}$ from a vertical orientation. In the target circle, the remaining line was always oriented vertically or horizontally. In the control condition, an additional premask was presented together with the regular premasks (Figure 1A). In the other conditions, an additional premask (distractor) was presented at a variable stimulus onset asynchrony (SOA) before or simultaneously with the presentation of the search array (Figure 1B). With the presentation of the search array, the additional premask changed in a similar fashion to the other nontarget circles.

The distractor was always presented at a distance of $9.5^{\circ}$ from the target. In $50 \%$ of the trials, the distractor was presented in the opposite hemifield from the target; in the remaining trials, the distractor and the target were presented in the same hemifield. Neither target nor distractor was ever presented on the vertical meridian. SOA (seven levels, including control) and hemifield (same, opposite) were randomized within blocks.

Procedure and Design. Participants received verbal instructions prior to the experiment. Participants were required to make a speeded response of the orientation of the line segment inside the uniquely colored circle by pressing the " $Z$ " key on presentation of a horizontal line segment and the "/" key on a vertical line segment. It was stressed that gaze should remain on the fixation point at all times and that accuracy should be around $90 \%$. Only during practice trials did participants receive immediate visual feedback upon an er- roneous response. Visual feedback was presented after every block, informing participants of their average RT and the number of errors. The experiment consisted of 48 practice trials and 700 experimental trials. Twenty-eight trials constituted a block, after each of which participants were given the opportunity to rest.

\section{Results}

One participant was excluded due to overly high RTs (average RT was more than 4 SDs above the grand mean). Trials in which the RT was either below $100 \mathrm{msec}$ or above $2,000 \mathrm{msec}(0.04 \%)$ were discarded, as were trials in which an erroneous manual response was given $(6.2 \%)$. In total, $93.8 \%$ of the trials were included in the analysis.

A repeated measures ANOVA using hemifield (same, opposite) and SOA (seven levels, including control) as within-subjects factors and mean correct RT as a dependent variable revealed a main effect of SOA $[F(6,138)=$ 25.59, $p<.0001]$ and an interaction between hemifield and SOA $[F(6,138)=12.30, p<.0001]$. There was no main effect of hemifield $(F<1)$. Planned comparisons revealed that in the 0 -msec SOA condition, RTs were slower for distractors presented in the same hemifield as the target $(M=664 \mathrm{msec}, S E=20.20$; see Figure 2$)$ than for distractors presented in the opposite hemifield from the target $[M=628 \mathrm{msec}, S E=18.28 ; t(23)=5.40, p<$ $.0001]$. The reverse pattern was found in the $-125-\mathrm{msec}$ SOA condition: RTs were faster for distractors presented in the same hemifield $(M=606 \mathrm{msec}, S E=17.71)$ than for those presented in the opposite hemifield from the target $[M=627 \mathrm{msec}, S E=18.81 ; t(23)=4.56, p<.001]$. 


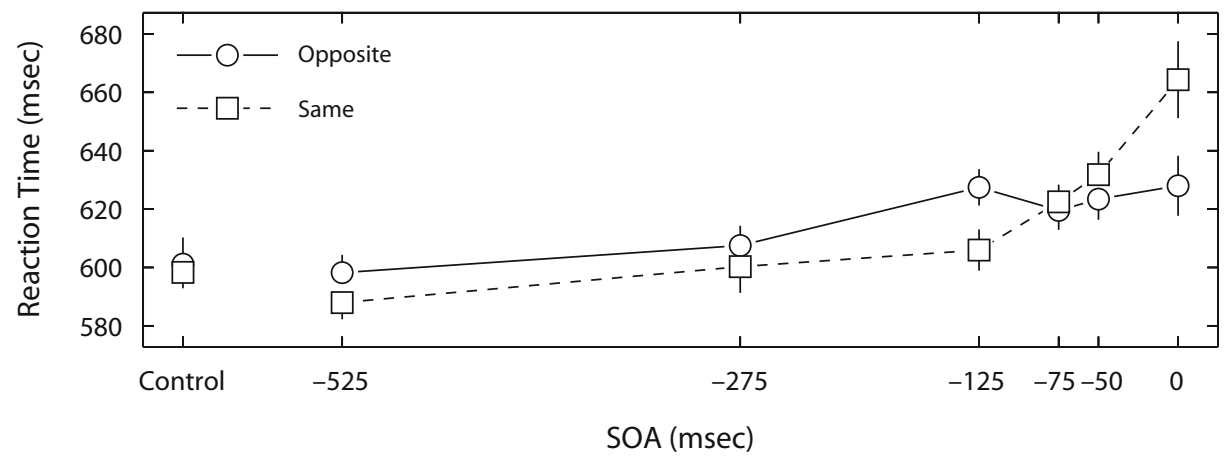

\begin{abstract}
Figure 2. The results of Experiment 1. When the distractor was presented sufficiently long before the target, there was maximal interference when the target and the distractor were presented in opposite visual fields. However, when the distractor was presented simultaneously with the target, there was maximal interference when they were presented within the same visual field. The error bars denote a $95 \%$ within-subjects confidence interval as outlined by Cousineau (2005). Overlapping error bars have been removed for clarity.
\end{abstract}

This was also the case for the $-525-\mathrm{msec}$ SOA condition $[M=588 \mathrm{msec}, S E=17.04$, vs. $M=598 \mathrm{msec}, S E=$ $17.61 ; t(23)=2.83, p<.01]$.

A repeated measures ANOVA using hemifield and SOA as within-subjects factors and the proportion of erroneous responses as a dependent variable revealed a main effect of SOA $[F(6,138)=5.00, p<.001]$. This effect was such that accuracy declined as the distractor and the target were presented in closer temporal succession. There were no other effects (all $F \mathrm{~s}<1)$.

\section{Discussion}

The results clearly show that when the target and the distractor were presented simultaneously there was less distractor interference when they were presented in opposite visual fields than when they were presented in the same visual field. This effect is consistent with previous studies and is believed to reflect competition for representation between the two simultaneously presented stimuli (Mounts \& Gavett, 2004; Sereno \& Kosslyn, 1991; Torralbo \& Beck, 2008). The influence of competitive interactions declined steeply as a small interstimulus interval was introduced, and appeared to be completely gone when the distractor was presented $75 \mathrm{msec}$ before the target. In addition, we observed a striking pattern reversal when the distractor was presented at longer intervals $(125 \mathrm{msec}$ or longer) before the target. In those cases, there was more distractor interference when the distractor was presented in the opposite visual field from the target. This can be explained in the more traditional view of reorienting the focus of attention (e.g., Jonides \& Yantis, 1988). Because of its sudden onset, attention was captured by the distractor. When at this point the target was presented, attention had to be reoriented toward the target. However, because attention is known to spread preferentially within a visual field (Hughes \& Zimba, 1985, 1987; Rizzolatti, Riggio, Dascola, \& Umiltà, 1987) it was less costly to reorient attention within a visual field than it was to reorient attention to a location in the opposite visual field.

\section{EXPERIMENT 2}

\section{Method}

Experiment 2 was identical to Experiment 1, except for the following differences: The observers were 34 students from the Vrije Universiteit, age range 17-30. Whereas in Experiment 1 the distractor was presented simultaneously with or prior to the target, in this experiment the distractor was presented simultaneously with or after the presentation of the target, using the following SOAs: 0, 50, 125 , and $275 \mathrm{msec}$. As in Experiment 1, in the control condition the distractor was presented simultaneously with the premasks. The experiment consisted of 80 practice trials and 480 experimental trials; 40 trials constituted a block.

\section{Results}

Trials in which the RT was either below $100 \mathrm{msec}$ or above $2,000 \mathrm{msec}(0.08 \%)$ were discarded, as were trials in which an erroneous manual response was given $(4.2 \%)$. In total, $95.8 \%$ of the trials were included in the analysis.

A repeated measures ANOVA using hemifield (same, opposite) and SOA (five levels, including control) as within-subjects factors and mean correct RT as a dependent variable revealed a main effect of SOA $[F(4,132)=$ $30.75, p<.0001]$, a main effect of hemifield $[F(1,33)=$ $7.91, p<.01]$, and an interaction between hemifield and $\operatorname{SOA}[F(4,132)=8.92, p<.0001]$. Planned comparisons revealed that in the 0 -msec SOA condition, RTs were slower for distractors presented in the same hemifield as the target $(M=717 \mathrm{msec}, S E=15.16$; see Figure 3) than for distractors presented in the opposite hemifield [ $M=$ $687 \mathrm{msec}, S E=14.52 ; t(33)=5.20, p<.0001]$. The same pattern was found in the 50-msec SOA condition $[M=697 \mathrm{msec}, S E=16.15$, vs. $M=681 \mathrm{msec}, S E=$ $15.47 ; t(33)=2.82, p<.01]$.

A repeated measures ANOVA using hemifield and SOA as within-subjects factors and the proportion of erroneous responses as a dependent variable revealed a main effect of SOA $[F(4,132)=3.38, p<.05]$, a marginally significant main effect of hemifield $[F(1,33)=3.09, p<.1]$, and a marginally significant interaction between hemi- 


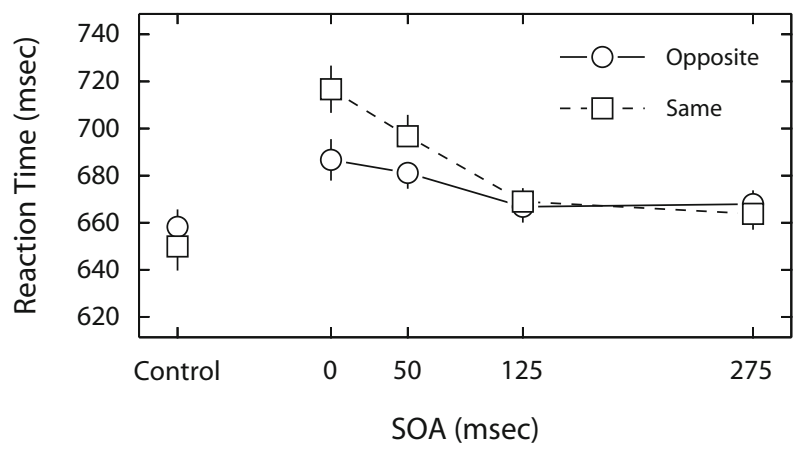

Figure 3. The results of Experiment 2. When the distractor was presented simultaneously with or shortly after the target, there was maximum interference when they were presented within the same visual field. However, this effect disappeared as the targetto-distractor interval increased. The error bars denote a $\mathbf{9 5 \%}$ within-subjects confidence interval as outlined by Cousineau (2005). Overlapping error bars have been removed for clarity.

field and SOA $[F(4,132)=2.32, p<.1]$. These accuracy effects mirrored the RT effects.

\section{Discussion}

As in Experiment 1, the results provide clear evidence for competition between the target and the distractor when they are presented simultaneously. Importantly, competition was also observed when the distractor was presented $50 \mathrm{msec}$ after the presentation of the target. This shows that even if processing of the target has already begun, competitive interactions with a subsequently presented stimulus can be disruptive. At longer SOAs (125 msec or more) there was no effect of hemifield. Presumably, at this point the target had been processed to the extent that subsequently presented stimuli exerted little or no effect on the forthcoming manual response.

\section{GENERAL DISCUSSION}

In the present study, we manipulated the level of competition between a target and a distractor stimulus by presenting them either in the same or in opposite visual fields, on opposite sides of the vertical meridian. Previous studies, both behavioral (Mounts \& Gavett, 2004; Sereno \& Kosslyn, 1991; Torralbo \& Beck, 2008) and neurophysiological (Chelazzi et al., 1998; Sato, 1988, 1989), have shown that competitive interactions are strongest between stimuli presented in the same visual field. This is what we also observed: If a distractor and a target stimulus are presented simultaneously, RTs are about $35 \mathrm{msec}$ slower when both stimuli are presented in the same visual field than when they are presented in opposite visual fields. The size of this RT difference is in the same range as previously reported in studies using similar measures (e.g., Sereno \& Kosslyn, 1991).

Importantly, we have shown that, in order for competition to arise, stimuli do not need to be presented at the exact same moment, although they do need to be presented in close temporal succession. In the present study, the "window of competition" was asymmetrical, since we observed competition if the target was presented $50 \mathrm{msec}$ before the distractor, but little, if any, competition if the distractor was presented $50 \mathrm{msec}$ before the target. Tentatively, this can be ascribed to the fact that the distractor was

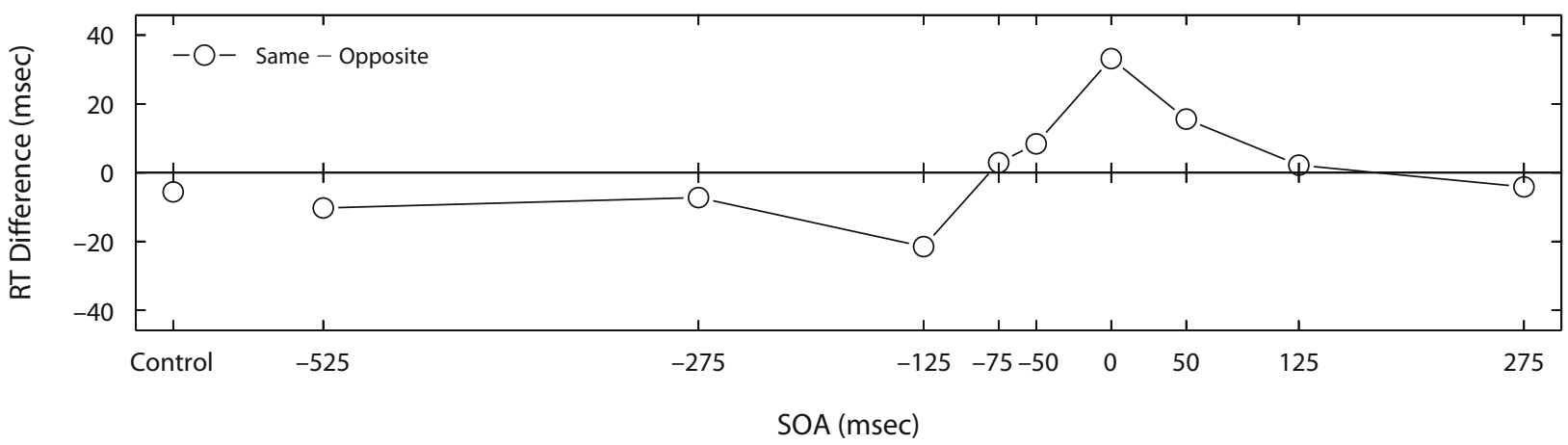

Figure 4. The difference in RT between same visual field and opposite visual field trials, as a function of SOA. Positive values correspond to faster responses on opposite visual field trials, indicative of competitive interactions. Negative values correspond to faster responses on same visual field trials, indicative of preferential reorienting of attention within a visual field. The data have been collapsed over Experiments 1 and 2. 
task irrelevant and therefore quickly inhibited (Theeuwes, Atchley, \& Kramer, 2000), thus failing to compete with the subsequently presented target. The target, on the other hand, was task relevant, therefore presumably not inhibited, and still strongly represented when the distractor was presented, resulting in competition.

Another important result was obtained when the distractor was presented prior to the target. As expected, we did not obtain evidence for direct competition between the target and the distractor at longer SOAs. However, we did obtain a striking pattern reversal: If the distractor was presented at least $125 \mathrm{msec}$ before the target, it caused more interference if the stimuli were presented in opposite visual fields rather than within the same visual field. This finding illustrates that attentional effects depend strongly on whether stimuli are presented consecutively or simultaneously (Reynolds \& Chelazzi, 2004). After a stimulus has captured attention, processing of another stimulus subsequently presented at the same location is facilitated. Importantly, the strength of attentional facilitation is not strictly confined to the initial locus of attention, but rather falls off with increasing distance (Connor, Gallant, Preddie, \& Van Essen, 1996; Connor, Preddie, Gallant, \& Van Essen, 1997). This has been demonstrated in a number of behavioral studies that show that the locus of attention is not sharply delimited but surrounded by a diffuse periphery receiving less, but still some, attentional benefit (Downing, 1988; Downing \& Pinker, 1985; Mangun \& Hillyard, 1988). Furthermore, it has been shown that this attentional benefit is greater for stimuli in the same visual field as the attended stimulus than for stimuli in the opposite hemifield (Hughes \& Zimba, 1985, 1987; Rizzolatti et al., 1987; Tassinari, Aglioti, Chelazzi, Marzi, \& Berlucchi, 1987). In the present study, the salient distractor presumably captured attention, even though it was task irrelevant (Theeuwes, 1991). To make an accurate report of the target, attention had to be reoriented to the target. The fact that reorienting attention is costly gives rise to a distractor interference effect, measured in the present study by increased RTs relative to the control condition. However, it is known that reorienting attention to a new location within the same visual field is less costly than reorienting attention to a new location in the opposite visual field (Rizzolatti et al., 1987). In our data, this is reflected by the fact that, at longer SOAs, distractor interference is greatest if the target and the distractor are presented in opposite visual fields.

In the present study, we have used the term visual field to refer to the left and right visual hemifields, which are separated by the vertical meridian. However, a number of studies have shown that there is also a cost of crossing the horizontal meridian (Rizzolatti et al., 1987; Umiltà, Riggio, Dascola, \& Rizzolatti, 1991); that is, if attention is allocated to some location, there is a cost of reorienting across the horizontal as well as the vertical meridian. In the present paradigm, we were unable to distinguish between these two meridian effects. If the target and the distractor were presented on the same side of the vertical meridian, they were presented on opposite sides of the horizontal meridian, and vice versa for targets and distractors on opposite sides of the vertical meridian. However, for a number of reasons we feel that an explanation in terms of the vertical meridian is appropriate. Most importantly, behavioral studies on biased competition have reported an effect of the vertical meridian but no effect of the horizontal meridian (e.g., Mounts \& Gavett, 2004). Furthermore, there is a clear anatomical separation between the left and the right cerebral hemispheres, and each of the two hemispheres deals predominantly with information from the contralateral visual field - at least in the early stages of visual processing (Desimone \& Schein, 1987; Gattass et al., 1988). Even in areas of the brain where the separation between visual fields is not as strict, there is less competition between stimuli presented on opposite sides of the vertical meridian but not of the horizontal meridian (Chelazzi et al., 1998).

An important implication of the present study is that a lack of direct competition does not imply that the relationship between stimuli is neutral. The presentation of a stimulus may affect processing of another stimulus, presented up to half a second later. This is an important consideration when investigating biased competition; manipulating whether stimuli are presented simultaneously or sequentially (e.g., Beck \& Kastner, 2005; Kastner et al., 1998) may yield results not solely due to the lack or presence of competitive interactions. Specifically, our results show that the effects of competitive interactions may in some cases appear larger than they really are, when operationalized as the difference between simultaneous and sequential presentation.

In summary, in the present study we investigated the temporal characteristics of distractor interference in the processing of a target stimulus. Specifically, we investigated how distractor interference varies as a function of whether a target and a distractor are presented in the same or in opposite visual fields. The most striking result is that the direction of this hemifield effect depends on whether stimuli are presented sequentially or simultaneously (see Figure 4). By combining direct competition and sequential presentation in a single paradigm, we have provided a clear demonstration of the dynamic nature of visual attention. Biased competition explains why target processing is disrupted if a target and a distractor are presented (almost) simultaneously. However, if a target and a distractor are presented sequentially, interference reflects the cost of reorienting attention from the distractor to the target.

\section{AUTHOR NOTE}

This research was funded by a grant from NWO (Netherlands Organization for Scientific Research) Grant 463-06-014 to J.T. Correspondence concerning this article should be addressed to S. Mathôt, Department of Cognitive Psychology, Vrije Universiteit Amsterdam, Van der Boechorststraat 1, $1081 \mathrm{HV}$ Amsterdam, The Netherlands (e-mail: s.mathot@psy.vu.nl).

\section{REFERENCES}

BAHCALl, D. O., \& Kowler, E. (1999). Attentional interference at small spatial separations. Vision Research, 39, 71-86.

BeCK, D. M., \& Kastner, S. (2005). Stimulus context modulates competition in human extrastriate cortex. Nature Neuroscience, $\mathbf{8}, 1110-$ 1116. 
BeCK, D. M., \& KASTNER, S. (2009). Top-down and bottom-up mechanisms in biasing competition in the human brain. Vision Research, 49, 1154-1165.

Caputo, G., \& Guerra, S. (1998). Attentional selection by distractor suppression. Vision Research, 38, 669-689.

Cave, K. R., \& Zimmerman, J. M. (1997). Flexibility in spatial attention before and after practice. Psychological Science, 8, 399-403.

Chelazzi, L., Duncan, J., Miller, E. K., \& Desimone, R. (1998). Responses of neurons in inferior temporal cortex during memory-guided visual search. Journal of Neurophysiology, 80, 2918-2940.

Connor, C. E., Gallant, J. L., Preddie, D. C., \& Van Essen, D. C. (1996). Responses in area V4 depend on the spatial relationship between stimulus and attention. Journal of Neurophysiology, 75, 1306-1308.

Connor, C. E., Preddie, D. C., Gallant, J. L., \& Van Essen, D. C. (1997). Spatial attention effects in macaque area V4. Journal of Neuroscience, 17, 3201-3214.

Cousineau, D. (2005). Confidence intervals in within-subject designs: A simpler solution to Loftus and Masson's method. Tutorials in Quantitative Methods for Psychology, 1, 42-45.

Desimone, R. (1998). Visual attention mediated by biased competition in extrastriate visual cortex. Philosophical Transactions of the Royal Society $B, \mathbf{3 5 3}, 1245-1255$.

Desimone, R., \& Duncan, J. (1995). Neural mechanisms of selective visual attention. Annual Review of Neuroscience, 18, 193-222.

Desimone, R., \& Schein, S. J. (1987). Visual properties of neurons in area V4 of the macaque: Sensitivity to stimulus form. Journal of Neurophysiology, 57, 835-868.

DownING, C. J. (1988). Expectancy and visual-spatial attention: Effects on perceptual quality. Journal of Experimental Psychology: Human Perception \& Performance, 14, 188-202.

Downing, C. J., \& PINKER, S. (1985). The spatial structure of visual attention. In M. I. Posner \& O. S. M. Marin (Eds.), Attention and performance XI (pp. 171-187). Hillsdale, NJ: Erlbaum.

Gattass, R., Sousa, A. P., \& Gross, C. G. (1988). Visuotopic organization and extent of V3 and V4 of the macaque. Journal of Neuroscience, $\mathbf{8}, 1831-1845$.

Hopf, J. M., Boehler, C. N., LucK, S. J., Tsotsos, J. K., HeinZe, H. J., \& Schoenfeld, M. A. (2006). Direct neurophysiological evidence for spatial suppression surrounding the focus of attention in vision. Proceedings of the National Academy of Sciences, 103, 1053-1058.

Hughes, H. C., \& Zimba, L. D. (1985). Spatial maps of directed visual attention. Journal of Experimental Psychology: Human Perception \& Performance, 11, 409-430.

Hughes, H. C., \& Zimba, L. D. (1987). Natural boundaries for the spatial spread of directed visual attention. Neuropsychologia, 25, 5-18.

Jonides, J., \& YANTIS, S. (1988). Uniqueness of abrupt visual onset in capturing attention. Perception \& Psychophysics, 43, 346-354.

Kastner, S., De Weerd, P., Desimone, R., \& Ungerleider, L. G. (1998). Mechanisms of directed attention in the human extrastriate cortex as revealed by functional MRI. Science, 282, 108-111.

Kastner, S., De Weerd, P., Pinsk, M. A., Elizondo, M. I., DesiMONE, R., \& UNGERLEIDER, L. G. (2001). Modulation of sensory suppression: Implications for receptive field sizes in the human visual cortex. Journal of Neurophysiology, 86, 1398-1411.

Keysers, C., \& Perrett, D. I. (2002). Visual masking and RSVP reveal neural competition. Trends in Cognitive Sciences, 6, 120-125.

Luck, S. J., Chelazzi, L., Hillyard, S. A., \& Desimone, R. (1997). Neural mechanisms of spatial selective attention in areas V1, V2, and V4 of macaque visual cortex. Journal of Neurophysiology, 77, 24-42.

Luck, S. J., Girelli, M., McDermott, M. T., \& Ford, M. A. (1997). Bridging the gap between monkey neurophysiology and human perception: An ambiguity resolution theory of visual selective attention. Cognitive Psychology, 33, 64-87.

Mangun, G. R., \& Hillyard, S. A. (1988). Spatial gradients of visual attention: Behavioral and electrophysiological evidence. Electroencephalography \& Clinical Neurophysiology, 70, 417-428.
Moran, J., \& Desimone, R. (1985). Selective attention gates visual processing in the extrastriate cortex. Science, 229, 782-784.

MotTer, B. C. (1993). Focal attention produces spatially selective processing in visual cortical areas V1, V2, and V4 in the presence of competing stimuli. Journal of Neurophysiology, 70, 909-919.

MounTs, J. R. W. (2000). Evidence for suppressive mechanisms in attentional selection: Feature singletons produce inhibitory surrounds. Perception \& Psychophysics, 62, 969-983.

MounTs, J. R. W., \& GAVETT, B. E. (2004). The role of salience in localized attentional interference. Vision Research, 44, 1575-1588.

PAN, K., \& ERIKSEN, C. W. (1993). Attentional distribution in the visual field during same-different judgments as assessed by response competition. Perception \& Psychophysics, 53, 134-144.

REYNolds, J. H., \& ChelazzI, L. (2004). Attentional modulation of visual processing. Annual Review of Neuroscience, 27, 611-647.

Reynolds, J. H., Chelazzi, L., \& Desimone, R. (1999). Competitive mechanisms subserve attention in macaque areas V2 and V4. Journal of Neuroscience, 19, 1736-1753.

Rizzolatti, G., Riggio, L., Dascola, I., \& Umiltà, C. (1987). Reorienting attention across the horizontal and vertical meridians: Evidence in favor of a premotor theory of attention. Neuropsychologia, $25,31-40$

Rocha-Miranda, C. E., Bender, D. B., Gross, C. G., \& Mishrin, M. (1975). Visual activation of neurons in inferotemporal cortex depends on striate cortex and forebrain commissures. Journal of Neurophysiology, 38, 475-491

SATO, T. (1988). Effects of attention and stimulus interaction on visual responses of inferior temporal neurons in macaque. Journal of Neurophysiology, 60, 344-364.

SATO, T. (1989). Interactions of visual stimuli in the receptive fields of inferior temporal neurons in awake macaques. Experimental Brain Research, 77, 23-30.

Sereno, A. B., \& Kosslyn, S. M. (1991). Discrimination within and between hemifields: A new constraint on theories of attention. Neuropsychologia, 29, 659-675.

Smith, A. T., Singh, K. D., Williams, A. L., \& Greenlee, M. W. (2001). Estimating receptive field size from fMRI data in human striate and extrastriate visual cortex. Cerebral Cortex, 11, 1182-1190.

Tassinari, G., Aglioti, S., Chelazzi, L., Marzi, C. A., \& BerlucCHI, G. (1987). Distribution in the visual field of the costs of voluntarily allocated attention and of the inhibitory after-effects of covert orienting. Neuropsychologia, 25, 55-71.

TheEUwES, J. (1991). Exogenous and endogenous control of attention: The effect of visual onsets and offsets. Perception \& Psychophysics, 49, 83-90.

Theeuwes, J. (1994). Stimulus-driven capture and attentional set: Selective search for color and visual abrupt onsets. Journal of Experimental Psychology: Human Perception \& Performance, 20, 799-806.

Theeuwes, J., Atchley, P., \& Kramer, A. F. (2000). On the time course of top-down and bottom-up control of visual attention. In S. Monsell \& J. Driver (Eds.), Control of cognitive processes: Attention and performance XVIII (pp. 105-124). Cambridge, MA: MIT Press.

Tombu, M., \& Tsotsos, J. K. (2008). Attending to orientation results in an inhibitory surround in orientation space. Perception \& Psychophysics, 70, 30-35.

Torralbo, A., \& Beck, D. M. (2008). Perceptual load-induced selection as a result of local competitive interactions in visual cortex. Psychological Science, 19, 1045-1050.

Tsotsos, J. K., Culhane, S. M., Kei Wai, W. Y., Lai, Y., Davis, N., \& Nuflo, F. (1995). Modeling visual attention via selective tuning. Artificial Intelligence, 78, 507-545.

Umiltà, C., Riggio, L., Dascola, I., \& Rizzolatti, G. (1991). Differential effects of central and peripheral cues on the reorienting of spatial attention. European Journal of Cognitive Psychology, 3, 247-267.

(Manuscript received October 20, 2008; revision accepted for publication October 28, 2009.) 